\title{
Eating disorders need more experimental psychopathology
}

Citation for published version (APA):

Jansen, A. (2016). Eating disorders need more experimental psychopathology. Behaviour Research and Therapy, 86, 2-10. https://doi.org/10.1016/j.brat.2016.08.004

Document status and date:

Published: $01 / 11 / 2016$

DOI:

10.1016/j.brat.2016.08.004

Document Version:

Publisher's PDF, also known as Version of record

Document license:

Taverne

\section{Please check the document version of this publication:}

- A submitted manuscript is the version of the article upon submission and before peer-review. There can be important differences between the submitted version and the official published version of record.

People interested in the research are advised to contact the author for the final version of the publication, or visit the DOI to the publisher's website.

- The final author version and the galley proof are versions of the publication after peer review.

- The final published version features the final layout of the paper including the volume, issue and page numbers.

Link to publication

\footnotetext{
General rights rights.

- You may freely distribute the URL identifying the publication in the public portal. please follow below link for the End User Agreement:

www.umlib.nl/taverne-license

Take down policy

If you believe that this document breaches copyright please contact us at:

repository@maastrichtuniversity.nl

providing details and we will investigate your claim.
}

Copyright and moral rights for the publications made accessible in the public portal are retained by the authors and/or other copyright owners and it is a condition of accessing publications that users recognise and abide by the legal requirements associated with these

- Users may download and print one copy of any publication from the public portal for the purpose of private study or research.

- You may not further distribute the material or use it for any profit-making activity or commercial gain

If the publication is distributed under the terms of Article $25 \mathrm{fa}$ of the Dutch Copyright Act, indicated by the "Taverne" license above, 


\title{
Eating disorders need more experimental psychopathology
}

\author{
Anita Jansen \\ Dept. of Clinical Psychological Science, Maastricht University, The Netherlands
}

\section{A R T I C L E I N F O}

\section{Article history:}

Received 17 January 2016

Received in revised form 30 July 2016

Accepted 8 August 2016

Available online 19 August 2016

\section{Keywords:}

Eating disorders

Experimental psychopathology

Anorexia nervosa

Bulimia nervosa

Binge eating disorder

Dietary restraint

Body dissatisfaction

Mechanisms of change

\begin{abstract}
A B S T R A C T
Eating disorders are severe and disabling mental disorders. The scientific study of eating disorders has expanded dramatically over the past few decades, and provided significant understanding of eating disorders and their treatments. Those significant advances notwithstanding, there is scant knowledge about key processes that are crucial to clinical improvement. The lack of understanding mechanisms that cause, maintain and change eating disorders, currently is the biggest problem facing the science of eating disorders. It hampers the development of really effective interventions that could be fine-tuned to target the mechanisms of change and, therefore, the development of more effective treatments. It is argued here that the science of eating disorders and eating disorder treatment could benefit tremendously from pure experimental studies into its mechanisms of change, that is, experimental psychopathology (EPP). To illustrate why eating disorders need more EPP research, some key symptoms - restriction of intake, binge eating and body overvaluation - will be discussed. EPP studies challenge some generally accepted views and offer a fresh new look at key symptoms. This will, consequently, better inform eating disorder treatments.
\end{abstract}

() 2016 Published by Elsevier Ltd.

\section{Introduction}

Eating disorders are severe, often disabling and frequently chronic mental disorders (Klump, Bulik, Kaye, Treasure, \& Tyson, 2009) with high mortality and suicide rates (Fichter \& Quadflieg, 2016; Hoang, Goldacre, \& James, 2014). They are characterised by overvaluation of weight/shape and abnormal eating, including severe restriction of food intake and/or frequent binge eating and purging behaviours, such as self-induced vomiting and misuse of laxatives. The striving for an ever thinner body leads to severe emaciation in anorexia nervosa (AN) while other eating disorder patients may range between slightly underweight and severely overweight. The lifetime prevalence of eating disorders is about $5 \%$ : $0,6 \%$ for $\mathrm{AN}, 1 \%$ for bulimia nervosa (BN) and 3\% for binge eating disorder (BED) (Treasure, Claudino, \& Zucker, 2010), while the prevalence of 'other specified feeding or eating disorders' and 'unspecified feeding or eating disorders' is not known. The scientific study of eating disorders has expanded dramatically over the past few decades (Theander, 2002). It has delivered significant understanding of the clinical dynamics of eating disorders, as well as knowledge of risk factors and the - generally limited - effects of treatments. Those significant advances notwithstanding, there is

E-mail address: a.jansen@maastrichtuniversity.nl. scant knowledge about the key processes that are crucial to clinical improvement. This lack of understanding about the mechanisms of change currently is the biggest problem facing the science of eating disorders. It hampers the development of really effective interventions that could be fine-tuned to target these mechanisms of change and, therefore, the development of more effective treatments.

In order to answer the seemingly simple question of which mechanisms have to be targeted in order to really reduce eating disorder psychopathology, an elaborate group of behavioural, cognitive, neurocognitive and interpersonal processes have to be taken into account. While an extensive range of sophisticated models on the development and maintenance of disordered eating were described, only a small percentage had progressed beyond mere description towards the development of interventions (Pennesi \& Wade, 2016) which is remarkable because the success rates of eating disorder treatments are, in general, modest. Many eating disorder patients drop out of treatment, do not or scarcely benefit from treatment, become chronic or soon relapse after an initial success (Bergh et al., 2013; Bulik, 2014; Galsworthy-Francis \& Allan, 2014; Watson \& Bulik, 2013). Effective treatments require understanding of the involved change mechanisms: why do treatments work? The experimental study of maintenance mechanisms and mechanisms of change, that is, the key processes that are crucial to clinical improvement, might help to advance the 
treatment of eating disorders. It is argued here that the science of eating disorders and eating disorder treatment could benefit tremendously from in particular experimental studies into these mechanisms.

\section{Methodological issues}

The methodological concerns in eating disorders research are not inherently different from other sciences (Van den Hout, Engelhard \& McNally, in press). Our knowledge of risk factors for the development of eating disorders expanded but most of the well-known risk factors come from cross-sectional studies and sometimes from longitudinal studies (Jacobi, Hayward, de Zwaan, Kraemer, \& Agras, 2004). These cross-sectional and longitudinal studies are well suited for the spotting of associations but they do not per se demonstrate causality, even not when the risk factor precedes the eating disorder symptoms in time. Though it is acknowledged that the study of risk factors is an important first step into factors involved in the development of eating disorders, as all causal factors are risk factors, temporal associations cannot simply be interpreted as causal associations, for other - 'third' variables could cause both the risk factor and the development of the eating disorder. Therefore, intervening on risk factors to prevent the development or worsening of eating disorders, is premature as long as its causal status is unknown: if the risk factor is not causal, the intervention might not be targeting the key mechanisms.

Likewise, randomised controlled trials (RCTs) intervene on alleged causal or maintaining factors during interventions, but they do not necessarily elucidate the mechanisms at work. Treatment usually means that many factors are manipulated at the same time while it is not precisely clear which components of the intervention are responsible for the treatment effect. The identification of mediators might represent potential mechanisms of change, but while mechanisms of change always are mediators, mediators are not always mechanisms of change (Kraemer, Wilson, Fairburn, \& Agras, 2002; Laurenceau, Hayes, \& Feldman, 2007). Besides, this could be considered a cumbersome way of searching for these mechanisms: RCTs require the opportunity to study large samples of eating disorder patients and carrying out a methodologically sound intervention study is an extremely laborious, costly and timeconsuming process. And if correlates are manipulated that are no risk or causal factors, the RCT is a waste of time (Kraemer, Stice, Kazdin, Offord, \& Kupfer, 2001).

It is not argued here that longitudinal studies and RCTs examining processes are not useful, on the contrary, they are very valuable. It is argued here that such a study requires, amongst other things, a strong theoretical model on the dynamics of eating disorders, in particular about the key processes that are crucial to clinical improvement. The testing of treatment effects and processes, using sophisticated models and analyses, is therefore preferably preceded by a research phase in which less costly and less time-consuming laboratory experiments are carried out to test the causality of alleged change mechanisms. Experimental psychopathology exactly does that.

\section{Experimental psychopathology (EPP)}

EPP refers to the experimental study of mental disorders; experimental psychopathologists bring psychopathology to the laboratory. They carry out well-controlled laboratory experiments with humans in which they manipulate variables that are assumed to be related to the appearance or disappearance of symptoms (Abramson \& Seligman, 1977; Van den hout et al., in press; Vervliet \& Raes, 2013). Experiments can provide a rigorous examination of clinical processes (Zvolensky, Lejuez, Stuart, \& Curtin, 2001) that do not merely describe clinical issues but try to explain and predict them (Van den hout et al., in press). EPP research is considered the interface between fundamental experimental psychology and clinical psychology (Van den hout et al., in press; Vervliet \& Raes, 2013; Zvolensky et al., 2001). To understand which factors cause or maintain eating disorders, the manipulation of these factors in well-controlled experimental studies is preferably tested in healthy, non-afflicted individuals. The researcher aims to mimic abnormal processes in healthy individuals by manipulating an alleged causal variable, to test whether the activation of this factor is sufficient for the hypothesised effect to occur. For example, if it is argued that emotional overeating follows from appetitive conditioning while in a sad mood, a laboratory study could study appetitive conditioning (e.g., a neutral cue is repeatedly followed by eating a piece of chocolate while another neutral cue is repeatedly followed by no intake) in healthy volunteers who are in a manipulated sad vs. neutral mood (e.g., by listening to sad or neutral music). If participants in the emotional condition (sad mood) eat significantly more than participants in the neutral control condition during a cued bogus taste test after appetitive conditioning, one can conclude that being emotional facilitates cued overeating. This hypothesis needed to be tested in healthy participants: if it was tested in a clinical or subclinical sample of emotional eaters, their test behaviour could follow from the emotional eating instead of leading to it. Emotional eaters might overeat after emotion induction because they always do this, while the researcher wants to know whether being emotional during appetitive conditioning induces cued overeating in healthy people.

There are ethical issues involved in the mimicking of symptoms in healthy non-afflicted participants by the manipulation of a variable (Zvolensky et al., 2001). This is especially true when experiments are done that potentially induce full psychopathology in healthy volunteers, which ethical committees will, rightly, not approve: ethical concerns constrain the severity of symptoms that can be induced (Sher \& Trull, 1996). The psychological manipulations that are used in typical EPP research are quite weak imitations of real causes, and also the effects are usually very weak imitations: mild symptoms of transient duration. In the example above, the induced sad mood is just short and mild lowering of one's mood and the test eating does not involve real binge eating but a relatively higher intake compared to a neutral condition who did not undergo the manipulation of the alleged cause. The aim is not to model an entire disorder or to induce full-blown symptoms, but to test causation: does the activation of factor A lead to the occurrence of the (miniature) symptom B?

Another way to determine the causal status of a factor, in addition to the induced mimicking of symptoms, is to reduce or remove the factor in analogue samples; nonclinical individuals who show subclinical symptoms. If the factor is causal, the symptoms will reduce when the factor is removed. For example, inhibition training reduces 'go' associations and intake in chocolate cravers (Houben \& Jansen, 2015) and mirror exposure increases body satisfaction in participants high in body dissatisfaction (Jansen, Voorwinde, Hoebink, Rekkers, Martijn \& Mulkens, 2016).

Both ways of studying causality, the induction and reduction of symptoms by manipulating (inducing vs. removing) the alleged causal or maintaining variable, are typical for EPP. It is a most valuable and effective way to learn more about mechanisms that maintain the disorder and, in this way, EPP findings might inform clinical treatment. The translation to actual clinical treatment is a next step in EPP research: removal of the hypothesised causal factor should reduce symptoms in patients. If it does, the EPP model has strong predictive validity, that is, "performance in the model predicts performance in the disorder" (Vervliet \& Raes, 2013, p. 2241). 
To illustrate why eating disorders need more EPP research, some key symptoms - restriction of intake, binge eating and body overvaluation - will be discussed. EPP studies challenge some generally accepted views and offer a fresh look at these key symptoms.

\section{Restriction of intake and food reward}

AN is characterised by a restriction of energy intake relative to requirements, leading to a significantly low body weight that is less than minimally normal. Notwithstanding the emaciation, there is an intense fear of gaining weight and becoming fat, leading to persistent behaviour that interferes with weight gain such as severe restriction by rigid dieting and high activity levels. Two subtypes are specified: a restricting type that is continuously restricting intake vs. a binge-eating \& purging subtype that alternates the restriction of intake with binge eating and purging behaviours (American Psychiatric Association, 2013).

We know little about the mechanisms that drive AN patients to defend low to extremely low body weights. The disorder is exceptionally difficult to treat, though treatment studies are scarce (Bulik, 2014). A series of cross-sectional studies show deviant neurobiological brain responses which led diverse experts to argue that AN is a neurobiological disorder (see e.g., Adan \& Kaye, 2011; Bulik, 2014; Ehrlich, Geisler, Ritschel, King, Seidel, Bohm et al., 2015; Klump et al., 2009; O'Hara, Campbell, \& Schmidt, 2015; Monteleone et al., 2016; Park, Godier, \& Cowdrey, 2014; Treasure et al., 2010). They stress the abnormal functioning of central reward systems in AN and state that this deregulated reward processing is central to the development of AN. The correlational knowledge that is provided by these cross-sectional studies comparing AN samples with healthy controls is however not necessarily informative about causal or maintaining mechanisms. The signalled differences between healthy people and AN patients might as well follow from the disorder, that is, they can be a consequence of starvation, emaciation, malnutrition or a typical 'anorectic' mindset and related cognitive processing. The associative findings therefore do not add much to an explanation of why some individuals deplete themselves from energy and defend severely low body weights in times of plenty.

Though there is not yet any empirical evidence for the idea that abnormal brain reward activity is causally related to voluntarily self-induced energy depletion or starvation in AN, a recent study showed identical reward deficiencies in individuals remitted from AN (Wierenga et al., 2015). Remission was defined by weight restoration though it is debatable whether weight restoration is sufficient for remission or recovery from an eating disorder. Defining remission by weight restoration only is a very narrow definition, thereby neglecting diagnostic issues like a fear of gaining weight, the disturbed weight or shape experience and the frequent relapses seen in eating disorders. It is questionable whether weight restored AN patients are actually in remission and therefore whether these findings reflect data from healthy participants.

A more plausible hypothesis is that intentional self-induced starvation leads to abnormal brain reward activity. Brain reward systems are strongly influenced by 'mindset' or top-down processes (e.g., Frankort et al., 2012; Giuliani, Mann, Tomiyama, \& Berkman, 2014; Roefs, Houben, \& Werthmann, 2015; Siep et al., 2012; Yokum \& Stice, 2013). Recent studies show that mindset not only influences eating behaviour but also one's physiological responding to food stimuli and actual nutrients (Cassady, Considine, \& Mattes, 2012; Crumm, Corbin, Brownell, \& Salovey, 2011; Frankort et al., 2012; Siep et al., 2012). Using functional Magnetic Resonance Imagery (fMRI), our lab demonstrated that healthy participants show an increased BOLD response in rewardrelated areas of the brain only when they focus on the palatability of food pictures ("imagine how good it tastes") (Frankort et al., 2012). It was also demonstrated that manipulations of mindset, by training a specific way of cognitive processing, influenced brain reward and control centers (Siep et al., 2012). Healthy participants were trained to either up-regulate, suppress or reappraise food palatability thoughts while activity in the rewardrelated areas of the brain was measured. In case of an up-regulation mindset, one had to actively think about the delicious smell, taste, and texture of the food cues in a way that would make the mouth water, e.g. "yummie, how good will the chocolate taste". In the suppression mindset, the task was to look at the food cue in a neutral way and to immediately inhibit or stop any thoughts about tastiness or cravings or about how good the food would be. The cognitive reappraisal mindset was to immediately think about the negative consequences of eating the food for health, weight and bodily appearance, e.g. "eating the chocolate will make me fat". Indeed, activity in reward-related brain areas was enhanced when healthy participants were in an up-regulation mindset while it was diminished when they were in the anorexic-like suppression or reappraisal mindset. Self-reported eating desires paralleled the brain reward activity (Siep et al., 2012). The study shows that cognitive strategies, or mindsets, can modulate brain responses to food stimuli and that it is possible to modulate, increase or reduce, appetitive motivation by inducing a specific mindset. Top-down processes influence the way one perceives or evaluates a food stimulus, and will determine whether brain activation is, for example, reward- or control- or anxiety related. AN's relentless pursuit of thinness, rigid dieting and self-starvation might be easier and more successful under conditions of a deliberate cognitive reappraisal of food palatability which, in its turn, leads to a reduction of the positive incentive value of foods. That is, foods may have become less desirable, and cause a relatively quick and automatic activation in top-down self-regulation brain regions (e.g., dorsolateral prefrontal cortex) and, at the same time, a deactivation of reward-related areas (Roefs et al., 2015; Pinel, Assanand \& Lehman, 2000). So it seems to be possible to modulate, increase, or reduce appetitive motivation by inducing a specific mindset.

Not only cognitive strategies are able to influence brain activation. A behavioural strategy that reduces reward activity in the brain is prolonged exposure to tasty food cues (smelling) without reinforcement, that is, without eating (Frankort et al., 2014). It seems that the habitual anorectic eating patterns function as a systematic and very effective extinction procedure. Individuals with AN frequently prepare delicious foods for other people but they do not (or hardly) eat it themselves. They also perform prolonged rituals when confronted with foods without eating a lot. In both ways, they frequently expose themselves to cues that usually signal intake while preventing actual intake, which will eventually lead to an extinction of appetitive responding (see e.g., Jansen, 1998; Jansen, Havermans, \& Nederkoorn, 2011; Jansen, Houben, \& Roefs, 2015; Jansen, Schyns, Bongers \& van den Akker, 2016). A recent neuroimaging study (Frankort et al., 2014) shows that prolonged exposure to tasty high-calorie foods without reinforcement (intensive smelling without eating) indeed leads to extinction of reward-related activity in the brain of healthy participants (chocolate lovers).

Note that this is not begging the question; not eating causes anorectic people to not eat. It is argued that frequent exposures without eating (response prevention), prototypical for AN, are necessary to reduce and eventually extinguish appetite. If one restricts eating while avoiding tempting food cues, like the smell and confrontation of very tasty foods, appetite will not extinguish. This might explain the difference between low calorie diets in obese vs. AN patients. Obese people tend to avoid tempting food cues and 
contexts during their diets while AN patients frequently expose themselves. Cued appetites will not extinguish in dieters who avoid tempting food cues, making them vulnerable for relapse.

In sum, a specific "anorexic" mindset can reduce brain reward activity and appetitive motivation, making it easier to refrain from eating when confronted with food. Not eating while preparing, seeing, smelling and tasting foods, in its turn, further extinguishes appetitive responding, including the neural responding in reward-related areas of the brain. This is exactly what AN patients permanently do. Such a reduction in reactivity to tempting food cues eliminates the primary motivation for eating, making it easier to restrict intake and, in the end, making it even impossible to eat.

If the abnormal, decreased reward activation follows from such a self-imposed extinction procedure, cognitive behavioural interventions that aim to renew the appetitive responding might restore the normal brain reward responding. Extinction is not unlearning (Bouton, 2002, 2011): AN patients do not forget or unlearn existing cue - intake associations, they still know the association between, for example, seeing/smelling tasty foods and the pleasure of eating them. Instead, extinction adds a new memory to the existing one: it is gradually learned that cues also predict severe restriction or even abstinence and after a while both body and brains will behave accordingly. The cue will therefore become ambiguous, it signals two possible actions: eating or not eating. The abstinence association can become very strong, especially in restricting AN patients, but the original association still exists and if activated in a proper way (Jansen, Schyns et al., 2016, Jansen, Voorwinde et al., 2016), it could be hypothesised that appetitive responding will return.

Extinction is largely context-dependent which might explain the huge relapse after clinical AN treatment. The eating regimen in a clinic might soon lead to renewed appetitive responding but when the patient returns home, i.e. to the context that is associated with abstinence (extinction), appetitive responding will be inhibited again. The implication for treatment would be that cued eating (cue exposure followed by intake) should be practiced in extinction contexts.

It is not argued here that extinguished appetites are at the heart of the disorder, it is hypothesised that reduced appetites and reduced brain reward responding follow from prototypical anorectic dietary habits. Central to these dietary habits are the core fear for weight gain and the relentless pursuit of thinness. A reexperience of eating tasty highly rewarding foods during exposures and a related return of eating desires might even induce more fear for weight gain. Treatments therefore should add new exposure modules that aim to reduce this fear by disconfirmation of uncontrollable and exponential weight gain expectancies, like recently described by Murray, Loeb, and LeGrange (2016).

\section{Restriction and binge eating}

Only a minority of eating disorder patients is successful in the permanent and rigid restriction of eating; these are the AN patients of the restricting subtype. Other eating disorder patients (AN patients of the binge/purge subtype, BN and BED) binge eat on a regular base. During an eating binge, control over eating is lost and a large amount of otherwise 'forbidden' high-calorie foods are eaten. An intriguing question is why people who want to restrict their intake to lose weight, binge eat on a regular base.

A generally accepted explanation for binge eating is that it follows from dieting, i.e., the deliberate restriction of food intake. Dieting is considered an important cause of binge eating. The evidence that links dieting and binge eating comes from a) retrospective clinical studies assessing the chronology between dieting and binge eating and b) laboratory studies. Several retrospective clinical reports describe patients remembering that they first lost weight and then started to binge eat (see for an overview of these studies Jacobi et al., 2004). However, these data rely on eating memories of eating disordered people who are prone to all kind of biases and are therefore, with a high degree of certainty, untrustworthy. Laboratory studies might be more informative.

In the sixties of last century, the social psychologist Stanley Schachter (1968) introduced an elegant and well-controlled experimental laboratory model of food intake regulation in obese vs. lean participants, which gave the first impulse to decades of fruitful experimental research on overeating. A couple of years later, Peter Herman suggested eating restraint was the critical variable, and not obesity per se though both would correlate (Herman \& Mack, 1975; Herman, Polivy, Pliner \& Threlkeld, Munic, 1978). They invited healthy weight students to the lab under the guise of taking part into a taste-test. The students were randomly assigned to a large vs. a small vs. no milkshake preload condition, which they were forced to consume. After consumption of the preload, bowls with ice cream were presented and participants were invited to eat as much as they wanted. Ad lib intake was compared between conditions and groups of high vs. low restrained eaters. It was found that low restrained eaters, i.e. participants without any weight or shape concerns who do not try to restrain their intake, compensated nicely for the preloads they ate: they ate a lot of ice cream after zero preload, a moderate amount after a small preload and a little bit after a large preload. Restrained eaters however, ate only a little bit of ice cream after zero preload and they ate significantly more ice cream after a small and a large preload. The authors described this behaviour as "counterregulation" and presented the paradigm as an experimental model of binge eating. This experimental model of binge eating appears to be a valid model because it describes the clinical picture quite well: binge eaters often report that eating a little bit of forbidden foods (i.e., breaking a diet) usually ends up in a binge (counterregulation, disinhibition).

Many more experiments showed that restrained eaters did not regulate their intake after their diets were broken by eating a highcalorie preload or after another disinhibitor was introduced, like alcohol consumption, smelling tasty foods, and emotion inductions (see e.g., Cools, Schotte, \& McNally, 1992; Herman \& Polivy, 1975; Hibscher \& Herman, 1977; Jansen \& van den Hout, 1991; Polivy, 1976; Polivy \& Herman, 1976; Ruderman \& Christensen, 1983) and researchers therefore concluded that dietary restraint causes overeating or binge eating and even eating disorders (e.g., Polivy \& Herman, 1985, 2002).

This conclusion, eating restraint causing overeating, binge eating and eating disorders, is still dominating the scientific and popular literature, though the conclusion is severely flawed because restraint was never manipulated in these experiments. Preloads, mood, alcohol ingestion and so on, were manipulated - so the only conclusion possible is that highly restrained eaters respond differently to forced consumption, mood induction and alcohol ingestion than unrestrained eaters. The data do however not enable to conclude that it is restraint that causes disinhibition, for restraint was not manipulated. Restrained and unrestrained eaters might differ in many respects, and all can be responsible for their differential response to a diverse range of disinhibitors. As long as dieting is not the manipulated variable, we cannot conclude that dieting is the cause of overeating.

Further, it is questionable whether the restrained eaters in these experimental studies were really restricting their food intake. In many of these experimental studies, restrained eaters had a higher Body Mass Index (BMI) than unrestrained eaters, and in the experiments they frequently ate more instead of less than 
unrestrained eaters. It appears that the often used self-report scales with the aim of selecting restrained eaters, like the Restraint Scale (Herman, Polivy, Pliner, Threlkeld, \& Munic, 1978) and the Dutch Eating Behaviour Questionnaire (Van Strien, Frijters, Bergers, \& Defares, 1986), are no pure and valid measures of actual food restriction (Jansen, 1996; Stice \& Durant, 2014; Stice, Sysko, Roberto, \& Allison, 2010): they rather measure weight concerns and an intention to restrain intake. Jansen (1996) demonstrated that selfreported restrained eaters ate significantly more than unrestrained eaters though they underestimated their intake and did not consider themselves overeating, which supports the idea of cognitive biases in self-reports of intake and restraint.

To find out whether calorie restriction is a real cause of overeating, studies should manipulate calorie restriction and test whether calorie restriction induces overeating. Some recent studies did. Animal studies showed calorie restriction (20-30\%) to be associated with greater longevity and better health (Heilbronn \& Ravussin, 2003; Roth \& Polotsky, 2012) and some human studies show that six months of calorie restriction beneficially affect measures of ageing and the prevention of age-related diseases (Heilbronn et al., 2006; Roth \& Polotsky, 2012; Tomiyama, 2012). Calorie restriction induces a lower body weight, less body fat, improved insulin and cholesterol levels, improved cardiovascular markers, and so on, while mood and quality of life increase (Teng et al., 2011). Considering food related issues, the experimental studies demonstrate no appetite increase during calorie restriction (25\% energy deficit) when compared with a weight stable control group (Anton et al., 2009). Others even report a reduction of hunger and increased eating control after a period of calorie restriction (Redman, Martin, Williamson, \& Ravussin, 2008; Williamson et al., 2008). There were no signs of eating disorder symptoms like overeating or binge eating, fear of fatness, or purging behaviour. Also clinical interventions in samples that are motivated to lose weight show that interventions which increase dietary restraint and calorie restriction result in weight loss, decreased rather than increased overeating, reduced binge eating frequency and reduced eating disorder symptoms (Burton \& Stice, 2006; Lowe \& Kral, 2006; Lowe \& Timko, 2007; Lowe, Gleaves, \& Murphy-Eberenz, 1998; Lowe, Witt, \& Grossman, 2013; Presnell \& Stice, 2003; Stice, Martinez, Presnell, \& Groesz, 2006; Stice, Presnell, Groesz, \& Shaw, 2005; Williamson et al., 2008).

To summarize, most studies that indicated an association between dietary restraint and binge eating were retrospective or of correlational nature, while clinical interventions and wellcontrolled experimental studies on calorie restriction demonstrate that actual calorie restriction does not naturally lead to binge eating or other eating disorder symptoms.

A more plausible explanation for the association between dietary restraint and binge eating is that dieting follows from overeating instead of the other way around. Some studies indeed put forward that intentions to limit calorie intake follow from the tendency to overeat or binge eat and that a restrained eating style reflects a fight against eating more than needed, instead of eating less than needed (Jansen et al., 2003; Lowe, 1993).

The tendency to overeat follows from increased reactivity to foods and cues that signal foods (Boswell \& Kober, 2016; Jansen, Schyns et al., 2016; Jansen, Voorwinde et al., 2016; Jansen et al., 2015; Nederkoorn \& Jansen, 2002). The responding to foods and food cues is called food cue reactivity and this reactivity is both psychological and physiological, such as an increased desire to eat or cravings, increased salivation, hormonal responding and neural reward activation. This entirety of appetitive responses to cues that signal the availability of food prepares the body for intake and motivates eating, also in the absence of hunger and in excess of calories needed. Though food cue reactivity during exposure to tasty foods is a normal and healthy response (Ferriday \& Brunstrom, 2011; Jansen, Nederkoorn, Roefs, Bongers, Teugels \& Havermans, 2011; Nederkoorn \& Jansen, 2002; Nederkoorn, Smulders, \& Jansen, 2000), reactivity is significantly stronger in binge eaters (including $\mathrm{BN}$ ) and obese people compared to people without eating or weight concerns (Boswell \& Kober, 2015; Brunstrom, Yates, \& Witcomb, 2004; Ferriday \& Brunstrom, 2011; Jansen, Stegerman, Roefs, Nederkoorn, \& Havermans, 2010; Legenbauer, Vögele \& Rüddel, 2004; Jansen et al., 2003; Nederkoorn, Smulders, Havermans, \& Jansen, 2004; Neudeck, Florin, \& Tuschen-Caffier, 2001; Tetley, Brunstrom, \& Griffiths, 2009; Van den Akker, Stewart, Antoniou, Palmberg, \& Jansen, 2014; Vögele \& Florin, 1997). These individual differences in food cue reactivity might follow from a genetic predisposition (Carnell, Haworth, Plomin, \& Wardle, 2008; Llewellyn, van Jaarsveld, Johnson, Carnell, \& Wardle, 2010) and/or learning experiences, as is shown in a series of human Pavlovian appetitive conditioning experiments (see for an overview: Jansen, Schyns et al., 2016, Jansen, Voorwinde et al., 2016). Critical are cues or contexts predicting calorie intake: the moment people learn that a cue or a context predicts the intake of highly rewarding foods, they will show (neuro-)biological reactivity and increased eating desires or food cravings in response to the cue or context.

This learning model of overeating/binge eating predicts that Pavlovian extinction is the way to decrease appetitive responding and overeating/binge eating (Jansen, 1998). The clinical analogue of extinction procedures in the lab is exposure with response prevention. During the exposure, the cues or contexts that signal intake remain systematically unreinforced, i.e., the associated tasty foods are not eaten, which is effective in decreasing cue reactivity or learned appetitive responding (Jansen, 1998; Jansen, Havermans et al., 2011; Jansen, Nederkoorn et al., 2011; Jansen, Schyns et al., 2016; Jansen, Voorwinde et al., 2016; Schyns, Roefs, Mulkens, \& Jansen, 2016). It was previously argued that the habitual eating patterns in AN might function as a systematic and very effective extinction procedure. While AN patients need to renew or reinstate appetitive responding, binge eaters (BN, BED) and overeaters (obesity) could profit from reduced appetitive responding. Several clinical case studies suggest that food cue exposure could be effective in the reduction of binge eating (Jansen, van den Hout, van Loof, Zandbergen, \& Griez, 1989; Jansen, Broekmate, \& Heymans, 1992; Toro et al., 2003; Martinez-Mallén et al., 2007). Two of these uncontrolled studies demonstrated excellent response to food cue exposure in severe BN patients who showed no or poor response to the evidence-based treatment of choice: cognitive behaviour therapy (Martinez-Mallén et al., 2007; Toro et al., 2003). Two methodologically well-controlled studies found that cue exposure reduced 'eating in the absence of hunger' of overweight and obese children and adults (Boutelle et al., 2011; Schyns et al., 2016).

To summarize, though the general view is that eating restraint leads to binge eating, experimental studies doubt this view. Experimentally induced eating restraint is not followed by increased binge eating or eating disorder symptoms, on the contrary; the diet manipulations lead to a decrease in binge eating and eating disorder symptoms. It thus seems more plausible that overeating or binge eating elicits a restrained eating style. Overeating in its turn appears to follow from increased food cue reactivity, which is easily learned. The learning model of overeating and binge eating puts forward that extinction procedures, like clinical exposure techniques, could be effective treatment modules to reduce increased appetitive responding, overeating and binge eating. 


\section{Body overvaluation}

A key symptom of eating disorders is severe body dissatisfaction. People with eating disorders often feel fat and unattractive; they show intense loathing of their bodies and are extremely afraid of gaining weight. People with AN are more successful than people with BN in their pursuit of thinness: while AN by definition is characterised by an abnormally low body weight, most people with BN have a normal or close to normal body weight. Current cognitive behavioural models of eating disorders argue that the so-called 'overvaluation' of shape and weight is at the heart of any eating disorder, regardless of diagnosis and actual weight: it is the 'core psychopathology' (Fairburn, 2008; Killen, Taylor, Hayward, Haydel, \& Wilson, 1996; Waller et al., 2011). Overvaluation means here that one's general self-worth depends largely or exclusively on the evaluation of shape and weight and the ability to control them. Shape and weight overvaluation has indeed been associated with the development, maintenance and relapse of eating disorders (Fairburn, Peveler, Jones, Hope, \& Doll, 1993; Johnson \& Wardle, 2005; Ricciardelli, Tate, \& Williams, 1997; Stice \& Shaw, 2002).

Eating disorder patients also show an abnormal fear of fatness that leads to an obsessive pursuit of thinness and compulsive body checking. An experimental manipulation of body checking in healthy female students shows that body checking behaviours induce biased attention for body-related cues and increased body dissatisfaction (Smeets, Tiggemann et al., 2011). This study and a couple of other experimental studies show that biased attention may play a pivotal role in the origin of body dissatisfaction. A selective visual attention bias was demonstrated in participants high in eating disorder symptoms by tracking eye movements during exposure to their own body vs. control bodies (Jansen, Nederkoorn, \& Mulkens, 2005). Eating disordered participants allocate more attention towards their self-defined unattractive body parts than to their self-defined attractive body parts. Healthy participants, on the contrary, do exactly the opposite: they focus more on their own attractive body parts and less on their own unattractive body parts. When looking at control bodies this pattern is reversed: eating disordered participants allocate less attention to the unattractive compared to the attractive parts of control bodies, while healthy participants focus more on the control's unattractive parts than to their attractive parts. It was concluded that a healthy way of looking is opposite to what eating disordered patients do (Jansen et al., 2005).

The dysfunctional way of looking at their own bodies was suggested to maintain body dissatisfaction and eating disorder psychopathology. However, the correlational nature of these data, showing exposure induced selective visual attention and increased body dissatisfaction in eating disorder symptomatic participants, precludes the drawing of conclusions about causality. If selective visual attention is indeed causal to increased body dissatisfaction, experimental manipulation of such a way of looking should induce increased dissatisfaction in healthy participants. To test its causal effects on body satisfaction, selective visual attention was then induced in healthy female students (Smeets, Jansen \& Roefs, 2011). To induce the attentional bias for one's self-defined attractive or unattractive body parts, an individually tailored attentional bias induction training was done. The participant, in front of a computer monitor, had to detect and identify the shape or colour of stimuli that appeared at different locations on a fuzzy (25\% visible) background picture of the participant's body or at neutral objects in the periphery. The identification of stimuli was controlled by an eye tracker: as soon as the participant's gaze matched the location of the stimulus, the body part or neutral object lightened up while the remainder of the body picture remained fuzzy. In this way, it was made sure that the participant looked at the specific body part the researchers wanted her to look at. She was instructed to keep looking at the illuminated body part that remained bright for a couple of seconds before the next stimulus had to be detected. In a first study, two conditions were manipulated: a negative bias training and a positive bias training. In the negative bias training, the stimulus appeared in $90 \%$ of the trials in one of three selfdefined most unattractive body parts. In the positive bias training, the stimulus appeared in $90 \%$ of the trials in one of three self-defined most attractive body parts. The healthy participants in the negative bias condition indeed showed a significant decrease in body satisfaction as a consequence of the negative bias training (Smeets, Jansen et al., 2011; Smeets, Tiggemann et al., 2011). The participants in the positive bias condition did not show an increase in body and weight satisfaction, but a positive counter induction training in the negative bias condition did lead to a significant increase in body satisfaction after it was experimentally decreased. So the positive training did not work in a sample that was relatively body satisfied (which might point to a ceiling effect) but it did work in a sample that was temporarily made body dissatisfied. In a second study, it was examined whether a short positive bias training would be effective in healthy individuals scoring high on body dissatisfaction (Smeets, Jansen et al., 2011; Smeets, Tiggemann et al., 2011). The control condition in this second study was a neutral training in which the stimulus appeared randomly on all possible body parts. Indeed, it was found that training body dissatisfied women to selectively attend their most attractive body parts led to an increase in body satisfaction, while body satisfaction in the control condition did not change (Smeets, Jansen et al., 2011; Smeets, Tiggemann et al., 2011). The experimental findings demonstrate a causal relationship between selective visual attention and body (dis)satisfaction: the manipulation of a bias towards negatively evaluated body parts decreases body satisfaction while the manipulation of a bias towards positively evaluated body parts increases body satisfaction. Elaborating on the findings of Jansen et al. (2005), it was shown that training healthy participants to view their bodies in a biased way, just as people with eating disorders do, results in increased feelings of body dissatisfaction. More precisely, a brief negative bias training made healthy participants feel worse about their bodies. As eating disorder patients have been shown to selectively attend to their own unattractive body parts (Jansen et al., 2005), it was suggested that repeatedly attending to these parts might not only cause but also maintain intense feelings of body dissatisfaction.

These experimental findings were then translated into a body exposure intervention in which attention is exclusively focused at one's self-defined attractive body parts (Jansen, Voorwinde et al, 2016). This 'positive' exposure was compared with a body exposure intervention that is more in use and that is mainly directed at focusing attention at one's self-defined unattractive body parts ('negative' exposure). Given the likelihood that underweight eating disordered patients would rank their most skinny-looking body parts as the most beautiful, training them to focus even more on these parts could increase their reluctance to gain weight, and even reinforce the glorification of their skinny bodies. Therefore, a healthy-weight student sample, non-clinical but high in body dissatisfaction, participated in the study. Contrary to expectations, both types of exposure effectively increased body satisfaction (Jansen, Schyns et al., 2016; Jansen, Voorwinde et al., 2016). Though the predicted effects in the experimental condition were found, the EPP groundwork did not predict the surprisingly positive effects in the control condition. It is still unclear why the 'negative' exposure increased body satisfaction as well, though the data suggests nice new hypotheses on the mechanism of change that should be tested in future experimental studies (see Jansen, Schyns et al., 2016; Jansen, Voorwinde et al., 2016). 
Another line of research into body dissatisfaction focused on evaluative conditioning interventions to increase body satisfaction (Martijn et al., 2013; Martijn, Vanderlinden, Roefs, Huijding, \& Jansen, 2010). It was argued that body dissatisfaction often is a 'social issue': the evaluation of one's own body usually is related to one's ideas of what other people would think. Healthy students, low and high in body satisfaction, were confronted with photos of their own body and bodies of other women. The bodies randomly appeared, one at a time, in one of four quadrants on a computer screen. By clicking on a photo another photo appeared: in the experimental condition, the photo of one's own body was always followed by a photo of a smiling face while control bodies were followed by neutral or frowning faces. In the control condition, smiling, neutral and frowning faces followed randomly the photos of one's own body and the control bodies (participants were not aware of these contingencies). Body satisfaction increased significantly in the experimental condition while it did not change in the control condition (Martijn et al., 2010). Especially participants who were high in body concerns showed a significant increase in body satisfaction when their bodies were followed by positive social feedback (smiling faces).

The intervention was then tested in a sample at high risk for the development of eating disorders (Aspen et al., 2015). Data showed decreased weight and shape concerns in the highly body dissatisfied sample at high risk for the development of eating disorders, and these positive findings were maintained at a 12-week followup. This study demonstrates the utility of an evaluative conditioning paradigm in a high-risk sample, a next step should be the testing of its potential utility in clinical practice.

\section{Conclusion}

In the last decades, the science of eating disorders delivered significant understanding of the clinical dynamics of eating disorders, as well as knowledge of risk factors and the - generally limited - effects of treatments. But still little is known about key processes that are crucial to clinical improvement. This lack of understanding about the mechanisms of change hampers the development of really effective interventions that could be fine-tuned to target these mechanisms. It is argued that in particular experimental studies into the mechanisms of interest, that is EPP, are of great value for the development of effective eating disorder treatments.

Cognitive Behaviour Therapy (CBT), currently the gold standard in the treatment of eating disorders, is a reasonably effective treatment for most eating disorders. However, there is considerable room for improvement, anorexia nervosa in particular but also BN and BED treatments could benefit from a better understanding of mechanisms of change. CBT is based on a cognitive behavioural model of eating disorders. The cognitive behavioural models - and therefore CBT treatments - all share the proposition that dietary restraint causes binge eating. They aim at a reduction of dieting behaviours. The experimental studies presented here do seriously doubt the validity of a 'restraint inducing binge eating' pathway. It is put forward that dieting follows binge eating or other forms of overeating, as a way to limit undesirable weight effects. Treatments therefore better could focus on reducing the propensity to binge eat or overeat, not by focusing on a reduction of (healthy) restraint but by reducing food cue reactivity through food cue exposure. AN treatment could, on the other hand, benefit from increasing reward feelings by doing proper food intake exposures, aiming at a renewal of extinguished desires to eat and a reduction of the fear to eat by disconfirmation of irrational weight gain expectancies.

All eating disorders might profit from new interventions to increase body satisfaction when at a healthy weight or overweight, like prolonged exposure to one's own body and/or the using of an evaluative conditioning paradigm in which one learns to associate one's own body with positive social feedback. The integration of these exposure elements with cognitive interventions, including behavioural experiments, might yield a new and more focused CBT - whereof the effectiveness still has to be determined.

It was intended to substantiate that for better focused eating disorder treatments knowledge of mechanisms that cause, maintain or change eating disorder symptoms, is needed. An efficient way to obtain that knowledge is provided by EPP. Experimental models of the eating disorder psychopathology predict an increase or reduction in eating disorder symptoms after activating or tackling the assumed maintaining or causal mechanisms. The EPP approach could inform clinical eating disorder treatments, and enables to determine which current treatment components are effective, necessary, sufficient, redundant or possibly even counterproductive. Eating disorders are very severe mental disorders: they need and deserve more experimental psychopathology.

\section{Acknowledgements}

This work is supported by the Netherlands Organisation for Scientific Research: VICI Grant 453.10.006, awarded to Anita Jansen.

\section{References}

Abramson, L. Y., \& Seligman, M. E. P. (1977). Modelling psychopathology in the laboratory: History and rationale. In J. D. Maser, \& M. E. P. Seligman (Eds.), Psychopathology: Experimental models (pp. 1-26). San Francisco: Freeman.

Adan, R. A. H., \& Kaye, W. H. (2011). Behavioral neurobiology of eating disorders Current topics in behavioral neurosciences 6. Berlin Heidelberg: Springer-Verlag. http://dx.doi.org/10.1007/7854_2010_82.

American Psychiatric Association. (2013). Diagnostic and statistical manual of mental disorders (5th ed.). Washington, DC: Author.

Anton, S. D., Han, H., York, E., Martin, C. K., Ravussin, E., \& Williamson, D. A. (2009). Effect of calorie restriction on subjective ratings of appetite. Journal of Human Nutrition and Dietetics, 22, 141-147. http://dx.doi.org/10.1111/j.1365277X.2008.00943.x.

Aspen, V., Martijn, C., Alleva, J. M., Nagel, J., Perret, C., Purvis, C., et al. (2015). Decreasing body dissatisfaction using a brief conditioning intervention. Behaviour Research and Therapy, 69, 93-99.

Bergh, C., Callmar, M., Danemar, S., Holcke, M., Isberg, S., Lundqvist, A., et al. (2013). Effective treatment of eating disorders: Results at multiple sites. Behavioral Neuroscience, 127, 878-889.

Boswell, R., \& Kober, H. (2016). Food cue reactivity and craving predict eating and weight gain: A meta-analytic review. Obesity Reviews, 17, 159-177.

Boutelle, K. N., Zucker, N. L., Peterson, C. B., Rydell, S. A., Cafri, G., \& Harnack, L. (2011). Two novel treatments to reduce overeating in overweight children: A randomized controlled trial. Journal of Consulting and Clinical Psychology, 79, 759-771. http://dx.doi.org/10.1037/a0025713.

Bouton, M. E. (2002). Context, ambiguity, and unlearning: Sources of relapse after behavioral extinction. Biological Psychiatry, 52, 976-986. http://dx.doi.org/ 10.1016/s0006-3223(02)01546-9.

Bouton, M. E. (2011). Learning and the persistence of appetite: Extinction and the motivation to eat and overeat. Physiology \& Behavior, 103, 51-58. http:// dx.doi.org/10.1016/j.physbeh.2010.11.025.

Brunstrom, J. M., Yates, H. M., \& Witcomb, G. L. (2004). Dietary restraint and heightened reactivity to food. Physiology \& Behavior, 81, 85-90. http:// dx.doi.org/10.1016/j.physbeh.2004.01.001.

Bulik, C. M. (2014). The challenges of treating anorexia nervosa. The Lancet 383(9912), 105-106. http://dx.doi.org/10.1016/S0140-6736(13)61940-6.

Burton, E., \& Stice, E. (2006). Evaluation of a healthy-weight treatment program for bulimia nervosa: A preliminary randomized trial. Behaviour Research and Therapy, 44, 1727-1738. http://dx.doi.org/10.1016/j.brat.2005.12.008.

Carnell, S., Haworth, C. M. A., Plomin, R., \& Wardle, J. (2008). Genetic influence on appetite in children. International Journal of Obesity, 32, 1468-1473. http:// dx.doi.org/10.1038/ijo.2008.127.

Cassady, B. A., Considine, R. V., \& Mattes, R. D. (2012). Beverage consumption, appetite, and energy intake: What did you expect? American Journal of Clinical Nutrition, 95, 587-593.

Cools, J., Schotte, D. E., \& McNally, R. J. (1992). Emotional arousal and overeating in restrained eaters. Journal of Abnormal Psychology, 101, 348-351.

Crumm, A. J., Corbin, W. R., Brownell, K. D., \& Salovey, P. (2011). Mind over Milkshakes: Mindsets, not just nutrients, determine ghrelin response. Health Psychology, 30, 424-429.

Ehrlich, S., Geisler, D., Ritschel, F., King, J. A., Seidel, M., Boehm, I., et al. (2015). Elevated cognitive control over reward processing in recovered female patients with anorexia nervosa. Journal of Psychiatry \& Neuroscience, 40, 307-315. http:// 
dx.doi.org/10.1503/jpn.140249.

Fairburn, C. G. (2008). Cognitive behavior therapy and eating disorders. New York: Guilford Press.

Fairburn, C. G., Peveler, R. C., Jones, R., Hope, R. A., \& Doll, H. A. (1993). Predictors of twelvemonth outcome in bulimia nervosa and the influence of attitudes to shape and weight. Journal of Consulting and Clinical Psychology, 61, 696-698.

Ferriday, D., \& Brunstrom, J. M. (2011). 'I just can't help myself': Effects of food-cue exposure in overweight and lean individuals. International Journal of Obesity, 35, $142-149$

Fichter, M. M., \& Quadflieg, N. (2016). Mortality in eating disorders - Results of a large prospective clinical longitudinal study. International Journal of Eating Disorders, 49, 391-401.

Frankort, A., Roefs, A., Siep, N., Roebroeck, A., Havermans, R., \& Jansen, A. (2012). Reward activity in satiated overweight women is decreased during unbiased viewing but increased during taste imagination: An event-related fMRI study. International Journal of Obesity, 36, 627-637.

Frankort, A., Roefs, A., Siep, N., Roebroeck, A., Havermans, R., \& Jansen, A. (2014). The craving stops before you feel it: Neural correlates of chocolate craving during cue exposure with response prevention. Cerebral Cortex, 24, 1589-1600.

Galsworthy-Francis, L., \& Allan, S. (2014). Cognitive behavioural therapy for anorexia nervosa: A systematic review. Clinical Psychology Review, 34, 54-72.

Giuliani, N. R., Mann, T., Tomiyama, A. J., \& Berkman, E. T. (2014). Neural systems underlying the reappraisal of personally craved foods. Journal of Cognitive Neuroscience, 26, 1390-1402.

Heilbronn, L. K., de Jonge, L., Frisard, M. I., DeLany, J. P., Larson-Meyer, D. E., Rood, J. et al. (2006). Effect of 6-Month calorie restriction on biomarkers of longevity, metabolic adaptation, and oxidative stress in overweight individuals. Journal of the American Medical Association, 295, 1539-1548. http://dx.doi.org/10.1001/ jama.295.13.1539.

Heilbronn, L. K., \& Ravussin, E. (2003). Calorie restriction and aging: Review of the literature and implications for studies in humans. American Journal of Clinical Nutrition, 78, 361-369.

Herman, C. P., \& Mack, D. (1975). Restrained and unrestrained eating. Journal of Personality, 43, 647-660.

Herman, C. P., \& Polivy, J. (1975). Anxiety, restraint, and eating behaviour. Journal of Abnormal Psychology, 84, 666-672.

Herman, C. P., Polivy, J., Pliner, P., Threlkeld, J., \& Munic, D. (1978). Distractibility in dieters and non-dieters: An alternative view of "externality". Journal of Per sonality and Social Psychology, 36, 536-548.

Hibscher, J. A., \& Herman, C. P. (1977). Obesity, dieting, and the expression of 'obese' characteristics. Journal of Comparative Physiology and Psychology, 91, 374-380.

Hoang, U., Goldacre, M., \& James, A. (2014). Mortality following hospital discharge with a diagnosis of eating disorder: National record linkage study, England, 2001-2009. International Journal of Eating Disorders, 47, 507-515. http:/ dx.doi.org/10.1002/eat.22249.

Houben, K., \& Jansen, A. (2015). Chocolate equals stop. Chocolate-specific inhibition training reduces chocolate intake and go associations with chocolate. Appetite 87, 318-323.

Jacobi, C., Hayward, C., de Zwaan, M., Kraemer, H. C., \& Agras, W. S. (2004). Coming to terms with risk factors for eating Disorders: Application of risk terminology and suggestions for a general taxonomy. Psychological Bulletin, 130, 19-65. http://dx.doi.org/10.1037/0033-2909.130.1.19.

Jansen, A. (1996). How restrained eaters perceive the amount they eat. British Journal of Clinical Psychology, 35, 381-392.

Jansen, A. (1998). A learning model of binge eating: Cue reactivity and cue exposure. Behaviour Research and Therapy, 36, 257-272.

Jansen, A., Broekmate, J., \& Heymans, M. (1992). Cue exposure vs self-control in the treatment of binge eating: A pilot study. Behaviour Research and Therapy, 30 235-241.

Jansen, A., Havermans, R., \& Nederkoorn, C. (2011). Cued overeating. In V. R. Preedy, R. R. Watson, \& C. R. Martin (Eds.), The international handbook of behavior, diet and nutrition (pp. 1431-1443). New York: Springer.

Jansen, A., Houben, K., \& Roefs, A. (2015). A cognitive profile of obesity and its translation into new interventions. Frontiers in Psychology, 6, 1807. http:/ dx.doi.org/10.3389/fpsyg.2015.01807.

Jansen, A., Nederkoorn, C., \& Mulkens, S. (2005). Selective visual attention for ugly and beautiful body parts in eating disorders. Behaviour Research and Therapy, 43, 183-196.

Jansen, A., Nederkoorn, Ch, Roefs, A., Bongers, P., Teugels, T. \& Havermans, R. (2011). The proof of the pudding is in the eating: Is the DEBQ - External eating scale a valid measure of external eating? International Journal of Eating Disorders, 44 164-168. http://dx.doi.org/10.1002/eat.20799.

Jansen, A., Schyns, G., Bongers, P., \& van den Akker, K. (2016). From lab to clinic: Extinction of cued cravings to reduce overeating. Physiology \& Behavior, 162, $174-180$.

Jansen, A., Stegerman, S., Roefs, A., Nederkoorn, C., \& Havermans, R. (2010). Decreased salivation to food cues in formerly obese successful dieters. Psychotherapy \& Psychosomatics, 79, 257-258. http://dx.doi.org/10.1159/ 000315131

Jansen, A., Theunissen, N., Slechten, K., Nederkoorn, C., Mulkens, S., \& Roefs, A. (2003). Overweight children overeat after exposure to food cues. Eating Behaviors, 4, 197-209.

Jansen, A., \& van den Hout, M. (1991). On being led into temptation: 'counterregulation' of dieters after smelling a 'preload'. Addictive Behaviors, 5, 247-253.

Jansen, A., van den Hout, M., van Loof, C., Zandbergen, J., \& Griez, E. (1989). A case of bulimia successfully treated with cue exposure. Behavior Therapy and Experimental Psychiatry, 20, 327-332.

Jansen, A., Voorwinde, V., Hoebink, Y., Rekkers, M., Martijn, C., \& Mulkens, S. (2016). Mirror exposure to increase body satisfaction: Should we guide the focus of attention towards positively or negatively evaluated body parts? Journal of Behavior Therapy and Experimental Psychiatry, 50, 90-96.

Johnson, F. J., \& Wardle, F. J. (2005). Dietary restraint, body dissatisfaction and psychological distress: A prospective analysis. Journal of Abnormal Psychology, $114,119-125$.

Killen, J. D., Taylor, C. B., Hayward, C., Haydel, K. F., \& Wilson, D. M. (1996). Weight concerns influence the development of eating disorders: A 4-year prospective study. Journal of Consulting and Clinical Psychology, 64, 936-940. http:/ dx.doi.org/10.1037/0022-006X.64.5.936.

Klump, K. L., Bulik, C. M., Kaye, W. H., Treasure, J., \& Tyson, E. (2009). Academy for eating disorders position paper: Eating disorders are serious mental illnesses. International Journal of Eating Disorders, 42, 97-103. http://dx.doi.org/10.1002/ eat.20589.

Kraemer, H. C., Stice, E., Kazdin, A., Offord, D., \& Kupfer, D. (2001). How do risk factors work together? Mediators, moderators, and independent, overlapping, and proxy risk factors. American Journal of Psychiatry, 158, 848-856.

Kraemer, H. C., Wilson, G. T., Fairburn, C. G., \& Agras, W. S. (2002). Mediators and moderators of treatment effects in randomized clinical trials. Archives of General Psychiatry, 59, 877-883.

Laurenceau, J.-P., Hayes, A. M., \& Feldman, G. C. (2007). Some methodological and statistical issues in the study of change processes in psychotherapy. Clinical Psychology Review, 27, 682-695.

Legenbauer, T., Vögele, C., \& Rüddel, H. (2004). Anticipatory effects of food exposure in women diagnosed with bulimia nervosa. Appetite, 42, 33-40.

Llewellyn, C. H., van Jaarsveld, C. H. M., Johnson, L., Carnell, S., \& Wardle, J. (2010). Nature and nurture in infant appetite. American Journal of Clinical Nutrition, 91 1172-1179. http://dx.doi.org/10.3945/ajen.2009.28868.

Lowe, M. R. (1993). The effects of dieting on eating behavior: A three-factor model. Psychological Bulletin, 114, 100-121.

Lowe, M. R., Gleaves, D. H., \& Murphy-Eberenz, K. P. (1998). On the relation of dieting and binging in bulimia nervosa. Journal of Abnormal Psychology, 107, 263-271.

Lowe, M. R., \& Kral, T. V. E. (2006). Stress-induced eating in restrained eaters may not be caused by stress or restraint. Appetite, 46, 16-21. http://dx.doi.org/ 10.1016/j.appet.2005.01.014.

Lowe, M. R., \& Timko, C. A. (2007). Dieting: Really harmful, merely ineffective or actually helpful? British Journal of Nutrition, 92(S1), S19. http://dx.doi.org/ 10.1079/BJN20041136.

Lowe, M. R., Witt, A. A., \& Grossman, S. L. (2013). Dieting in bulimia nervosa is associated with increased food restriction and psychopathology but decreased binge eating. Eating Behaviors, 14, 342-347. http://dx.doi.org/10.1016/ j.eatbeh.2013.06.011.

Martijn, C., Sheeran, P., Wesseldijk, L. W., Merrick, H., Webb, T. L., Roefs, A., et al. (2013). Evaluative conditioning makes slim models less desirable as standards for comparison and increases body satisfaction. Health Psychology, 32, 433-438. http://dx.doi.org/10.1037/a0028592.

Martijn, C., Vanderlinden, M., Roefs, A., Huijding, J., \& Jansen, A. (2010). Increasing body satisfaction of body concerned women through evaluative conditioning using social stimuli. Health Psychology, 29, 514-520. http://dx.doi.org/10.1037/ a0020770.

Martinez-Mallén, E., Castro-Fornieles, J., Lázaro, L., Moreno, E., Morer, A., Font, E., et al. (2007). Cue exposure in the treatment of resistant adolescent bulimia nervosa. International Journal of Eating Disorders, 40, 596-601.

Monteleone, A. M., Monteleone, P. Grave, R. D., Nigro, M. Ghoch El, M., Calugi, S., et al. (2016). Ghrelin response to hedonic eating in underweight and short-term weight restored patients with anorexia nervosa. Psychiatry Research, 235, 55-60.

Murray, S. B., Loeb, K. L., \& LeGrange, D. (2016). Dissecting the core fear in anorexia nervosa. Can we optimize treatment mechanisms? JAMA Psychiatry. http:// dx.doi.org/10.1001/jamapsychiatry.2016.1623 (in press).

Nederkoorn, C., \& Jansen, A. (2002). Cue reactivity and regulation of food intake. Eating Behaviors, 3, 61-72.

Nederkoorn, C., Smulders, F., Havermans, R., \& Jansen, A. (2004). Exposure to binge food in bulimia nervosa: Finger pulse amplitude as a potential measure of urge to eat and predictor of food intake. Appetite, 42, 125-130.

Nederkoorn, C., Smulders, F., \& Jansen, A. (2000). Cephalic phase responses, craving and food intake in normal subjects. Appetite, 35, 45-55.

Neudeck, P., Florin, I., \& Tuschen-Caffier, B. (2001). Food exposure in patients with bulimia nervosa. Psychotherapy and Psychosomatics, 70, 193-200.

O'Hara, C. B., Campbell, I. C., \& Schmidt, U. (2015). A reward-centred model of anorexia nervosa: A focussed narrative review of the neurological and psychophysiological literature. Neuroscience \& Biobehavioral Reviews, 52, 131-152. http://dx.doi.org/10.1016/j.neubiorev.2015.02.012.

Park, R. J., Godier, L. R., \& Cowdrey, F. A. (2014). Hungry for reward: How can neuroscience inform the development of treatment for Anorexia Nervosa? Behaviour Research and Therapy, 62, 47-59. http://dx.doi.org/10.1016/ j.brat.2014.07.007.

Pennesi, J.-L., \& Wade, T. D. (2016). A systematic review of the existing models of disordered eating: Do they inform the development of effective interventions? Clinical Psychology Review, 43, 175-192.

Pinel, J. P., Assanand, S., \& Lehman, D. R. (2000). Hunger, eating, and ill health. The 
American Psychologist, 55, 1105-1116.

Polivy, J. (1976). Perception of calories and regulation of intake in restrained and unrestrained subjects. Addictive Behaviours, 1, 237-243.

Polivy, J., \& Herman, C. P. (1976). Effects of alcohol on eating behavior: Influence of mood and perceived intoxication. Journal of Abnormal Psychology, 85, 601-606.

Polivy, J., \& Herman, C. P. (1985). Dieting and bingeing. A causal analysis. American Psychologist, 40, 193-201.

Polivy, J., \& Herman, C. P. (2002). Causes of eating disorders. Annual Review of Psychology, 53, 187-213.

Presnell, K., \& Stice, E. (2003). An experimental test of the effect of weight-loss dieting on bulimic pathology: Tipping the scales in a different direction. Journal of Abnormal Psychology, 112, 166-170.

Redman, L. M., Martin, C. K., Williamson, D. A., \& Ravussin, E. (2008). Effect of caloric restriction in non-obese humans on physiological, psychological and behavioral outcomes. Physiology \& Behavior, 94, 643-648. http://dx.doi.org/10.1016/ j.physbeh.2008.04.017.

Ricciardelli, L. A., Tate, D., \& Williams, R. J. (1997). Body dissatisfaction as a mediator of the relationship between dietary restraint and bulimic eating patterns. Appetite, 29, 43-54. http://dx.doi.org/10.1006/appe.1997.0093.

Roefs, A., Houben, K., \& Werthmann, J. (2015). Desire for food and the power of mind. In W. Hofmann, \& L. F. Norgren (Eds.), The psychology of desire (pp. 323-346). New York: Guilford Press.

Roth, L. W., \& Polotsky, A. J. (2012). Can we live longer by eating less? A review of caloric restriction and longevity. Maturitas, 71, 315-319. http://dx.doi.org/ 10.1016/j.maturitas.2011.12.017.

Ruderman, A. J., \& Christensen, H. (1983). Restraint theory and its applicability to overweight individuals. Journal of Abnormal Psychology, 92, 210-215.

Schachter, S. (1968). Obesity and eating. Science, 161(3843), 751-756. http:// dx.doi.org/10.1126/science.161.3843.751.

Schyns, G., Roefs, A., Mulkens, S., \& Jansen, A. (2016). Expectancy violation, reduction of food cue reactivity and less eating in the absence of hunger after one food cue exposure session for overweight and obese women. Behaviour Research and Therapy, 76, 57-64.

Sher, K. J., \& Trull, T. J. (1996). Methodological issues in psychopathology research. Annual Review of Psychology, 47, 371-400.

Siep, N., Roefs, A., Roebroeck, A., Havermans, R., Bonte, M. L., \& Jansen, A. (2012). Fighting food temptations: The modulating effects of short-term cognitive reappraisal, suppression and up-regulation on mesocorticolimbic activity related to appetitive motivation. Neuroimage, 60, 213-220.

Smeets, E., Jansen, A., \& Roefs, A. (2011). Bias for the (un)attractive self: On the role of attention in causing body (dis)satisfaction. Health Psychology, 30, 360-367. http://dx.doi.org/10.1037/a0022095.

Smeets, E., Tiggemann, M., Kemps, E., Mills, J. S., Hollitt, S., Roefs, A., et al. (2011). Body checking induces an attentional bias for body-related cues. International Journal of Eating Disorders, 44, 50-57. http://dx.doi.org/10.1002/eat.20776.

Stice, E., \& Durant, S. (2014). Elevated objectively measured but not self-reported energy intake predicts future weight gain in adolescents. Appetite, 81, 84-88. http://dx.doi.org/10.1016/j.appet.2014.06.012.

Stice, E., Martinez, E. E., Presnell, K., \& Groesz, L. M. (2006). Relation of successful dietary restriction to change in bulimic symptoms: A prospective study of adolescent girls. Health Psychology, 25, 274-281. http://dx.doi.org/10.1037/ 0278-6133.25.3.274.

Stice, E., Presnell, K., Groesz, L., \& Shaw, H. (2005). Effects of a weight maintenance diet on bulimic symptoms in adolescent girls: An experimental test of the dietary restraint theory. Health Psychology, 24, 402-412.
Stice, E., \& Shaw, H. E. (2002). Role of body dissatisfaction in the onset and maintenance of eating pathology: A synthesis of research findings. Journal of Psychosomatic Research, 53, 985-993. http://dx.doi.org/10.1016/s0022-3999(02) 00488-9.

Stice, E., Sysko, R., Roberto, C. A., \& Allison, S. (2010). Are dietary restraint scales valid measures of dietary restriction? Additional objective behavioral and biological data suggest not. Appetite, 54, 331-339.

Teng, N. I. M. F., Shahar, S., Manaf, Z. A., Das, S. K., Taha, C. S. C., \& Ngah, W. Z. W. (2011). Efficacy of fasting calorie restriction on quality of life among aging men. Physiology \& Behavior, 104, 1059-1064. http://dx.doi.org/10.1016/ j.physbeh.2011.07.007.

Tetley, A., Brunstrom, J., \& Griffiths, P. (2009). Individual differences in food-cue reactivity. The role of BMI and everyday portion-size selections. Appetite, 52, 614-620.

Theander, S. S. (2002). Literature on eating disorders during 40 Years: increasing number of papers, emergence of bulimia nervosa. European Eating Disorders Review, 10, 386-398. http://dx.doi.org/10.1002/erv.495.

Tomiyama, A. J. (2012). Beyond interventions: Caloric restriction as a scientific model. Psychosomatic Medicine, 74, 665-666. http://dx.doi.org/10.1097 PSY.0b013e31825fe211.

Toro, J., Cervera, M., Feliu, M. H., Garriga, N., Jou, M., Martinez, E., et al. (2003). Cue exposure in the treatment of resistant bulimia nervosa. The International journal of eating disorders, 34, 227-234. http://dx.doi.org/10.1002/eat.10186.

Treasure, J., Claudino, A. M., \& Zucker, N. (2010). Eating disorders. The Lancet, 375, 583-593. http://dx.doi.org/10.1016/S0140-6736(09)61748-7.

Van Strien, T., Frijters, J. E. R., Bergers, G. P. A., \& Defares, P. B. (1986). Handleiding Nederlandse Vragenlijst voor Eetgedrag. Lisse: Zwets and Zeitlinger.

Van den Akker, K., Stewart, K., Antoniou, E. E., Palmberg, A., \& Jansen, A. (2014). Food cue reactivity, obesity, and impulsivity: Are they associated? Current Addiction Reports, 1, 301-308.

Van den Hout, M., Engelhard, I. M., \& McNally, R. J. (2016). Thoughts on experimental psychopathology. Psychopathology Review (in press).

Vervliet, B., \& Raes, F. (2013). Criteria of validity in experimental psychopathology: Application to models of anxiety and depression. Psychological Medicine, 43, 2241-2244.

Vögele, C., \& Florin, I. (1997). Psychophysiological responses to food exposure: An experimental study in binge eaters. International Journal of Eating Disorders, 21, 147-157.

Waller, G., Cordery, H., Corstorphine, E., Hinrichsen, H., Lawson, R., Mountford, V. et al. (2011). Cognitive behavioural therapy for eating disorders. A comprehensive treatment guide. Cambridge: Cambridge University Press.

Watson, H. J., \& Bulik, C. M. (2013). Update on the treatment of anorexia nervosa: Review of clinical trials, practice guidelines and emerging interventions. Psychological Medicine, 43, 2477-2500.

Wierenga, C. E., Bischoff-Grethe, A., Melrose, A. J., Irvine, Z., Torres, L., Bailer, U. F. et al. (2015). Hunger does not motivate reward in women remitted from anorexia nervosa. Biological Psychiatry, 77, 642-652.

Williamson, D. A. Martin, C. K., Anton, S. D., York-Crowe, E., Han, H., \& Redman, L. (2008). Is caloric restriction associated with development of eating-disorder symptoms? Results from the CALERIE trial. Health Psychology, 27, S32-S42.

Yokum, S., \& Stice, E. (2013). Cognitive regulation of food craving: Effects of three cognitive reappraisal strategies on neural response to palatable foods. International Journal of Obesity, 37, 1565-1570.

Zvolensky, M. J., Lejuez, C. W., Stuart, G. L., \& Curtin, J. J. (2001). Review of General Psychology, 5, 371-381. 